\title{
A Study on the Mechanical Properties for Ternary Polymer Blends
}

\author{
Awham M. Hameed ${ }^{1}$ \\ ${ }^{1}$ Applied sciences Department, University of Technology, Baghdad, Iraq \\ Correspondence: Awham M. Hameed, Applied sciences Department, University of Technology, Baghdad, Iraq. \\ E-mail: awham_m@yahoo.com
}

Received: May 19, 2017

doi:10.5539/jmsr.v6n3p27
Accepted: June 21, 2017

Online Published: June 30, 2017

URL: https://doi.org/10.5539/jmsr.v6n3p27

\begin{abstract}
In this work, two ternary polymer blends were prepared by mixing EP with (UP/PSR) and (PVC/PSR) respectively. Different mixing ratios were used $(5,10,15$ and 20$) \mathrm{wt} . \%$ of the added polymers. Impact, tensile, compression, flexural and hardness tests were performed on the prepared blends. The results of testing showed that the first ternary blend A (EP/UP/PSR) records tensile strength values higher than that of the second ternary blend $\mathrm{B}(\mathrm{EP} /$ $\mathrm{PVC} / \mathrm{PSR}$ ). At $20 \mathrm{wt} . \%$ of mixing, the blend $\mathrm{B}$ records higher impact strength than that of the blend $\mathrm{A}$. There is large difference in the flexural behavior between $\mathrm{A}$ and $\mathrm{B}$ blends where the blend $\mathrm{A}$ records the highest value of flexural strength (F.S) at (5wt.\%) while the blend B records the highest value of (F.S) at (20wt.\%). From compression test, it is obvious that the values of compressive strength decrease of blend B more than that of the blend $\mathrm{A}$ as well as the same behavior can be obtained through the hardness test.
\end{abstract}

Keywords: Ternary blends, Epoxy, Unsaturated polyester, PVC, PSR

\section{Introduction}

It is well known that epoxy is the most common polymer in many applications such as (matrix of composite, coatings, adhesives and insulators and others) (Kumar \& Kothandaraman, 2008).

Polymer blends are physical mixtures of two or more polymers with and without any chemical bonding between them. These polymers are mixed together to improve the properties of the original polymer as well as to reduce the cost (Zhu et al., 2013).

Some researchers interested in this type of materials for example:

Ban (Zhu et al., 2013) prepared two ternary blends; the first consists of epoxy resin and novolac resin mixed with polysulphide rubber (PSR). The second consists of polyurethane with epoxy resin and novolac resin with different weight ratios. The optimum mixing ratios were selected and reinforced with $\left(\mathrm{TiO}_{2}\right)$ powder. The result shows that these blends have better mechanical properties such as impact, compressive and tensile strength, hardness and wear resistance.

Arunhati and Arun (2011) prepared a blend consists of epoxy resin blended with thiol terminated liquid polysulfide rubber for $(10,20$ and $30 \mathrm{phr})$ and cured with phthalic anhydride curing agent at $\left(130^{\circ} \mathrm{C}\right.$ for $5 \mathrm{hrs}$.). Tensile strength and hardness values of the blend decreased with increase in the Thiokol terminated liquid polysulfide content but the values of impact strength and elongation increased with increase in the Thiokol terminated liquid polysulfide content. The fracture surface analysis was studied by SEM and found that it has two-phase morphology.

This paper aims to carry out some modifying in the properties of epoxy resin for improving the toughness value of it. Also the work is interesting in studying the mechanical behavior of ternary blends (EP/UP/PSR) and (EP/PVC/PSR).

\section{Experimental}

Two ternary blends were prepared in this work, the first is named (EP/UP/ PSR) and the second is (EP/PVC/PSR).

\subsection{Materials}

\subsubsection{Epoxy resins (EP):}

Epoxy resin (EP) is the first material in the blending process and the other materials added to it. The percentage of (EP) which were used included $(95,90,85,80 \mathrm{wt} . \%)$. The mixing ratio of this resin with its hardener is equal (3/1). 


\subsubsection{Unsaturated polyester resin (UP):}

It is the second material that added to Epoxy resin with percentages $(2.5,5,7,10 \mathrm{wt}$. \%). The mixing ratio of this resin with its hardener is equal ( $2 \mathrm{~g}$ of hardener for each $100 \mathrm{~g}$ of resin)

\subsubsection{Polysulfide rubber (PSR):}

It is the third material that added to prepare the first ternary blend with the same percentages of the second polymer $(2.5,5,7,10$ wt. \%). The mixing ratio of this resin with its hardener is equal (4/1).

\subsubsection{Polyvinyl chloride (PVC):}

This material is used as third material to prepare the second ternary blend that consists of (EP), (PVC) and (PSR), and the percentages of this blend are the same of the first ternary blend.

\subsection{Mechanical Tests}

\subsubsection{Tensile Test}

Tensile machine manufactured by the company (JIANQIAO), made in China was used in this work. The sample was put vertically between the two jaws of the device as shown in the Figure 1.

Figure 2 shows the tensile test samples before and after the test.

The values of ultimate tensile strength (UTS) can be calculated by applying the following equation (Young \& Budynas, 2002):

$$
\mathrm{UTS}=\frac{F_{\max }}{A}
$$

where $\left(F_{\max }\right)$ is the maximum force required to fracture the sample, $(\mathrm{A})$ is the cross sectional area of the sample $\left(\mathrm{mm}^{2}\right)$.

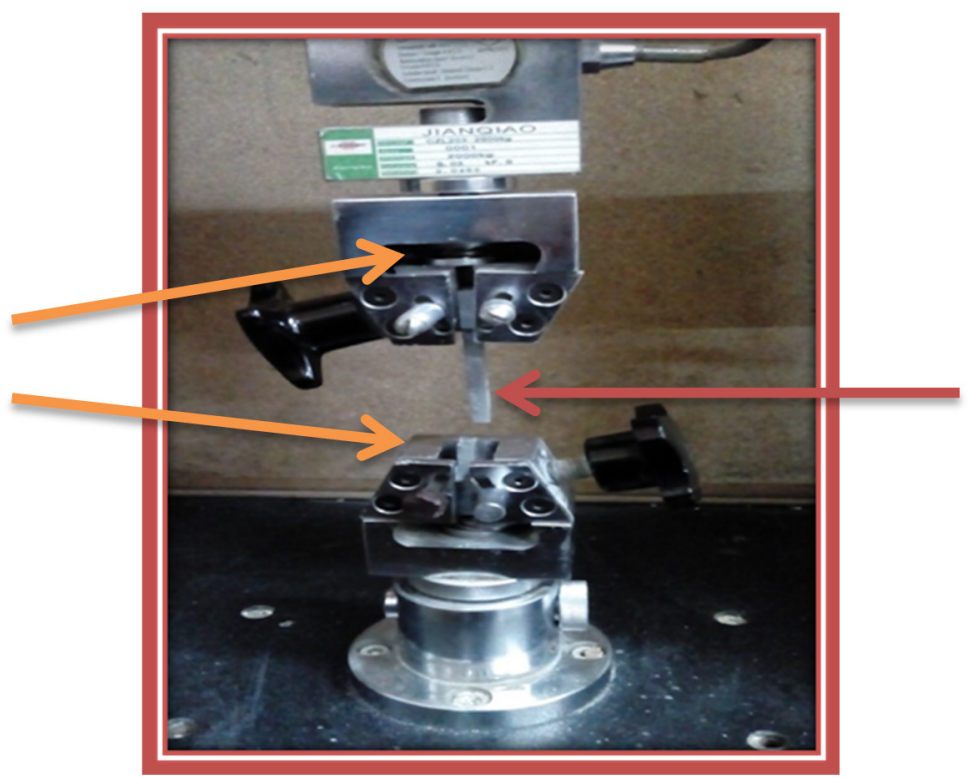

Figure 1. Tensile machine photograph and the fracture of sample subjected to the tension load 


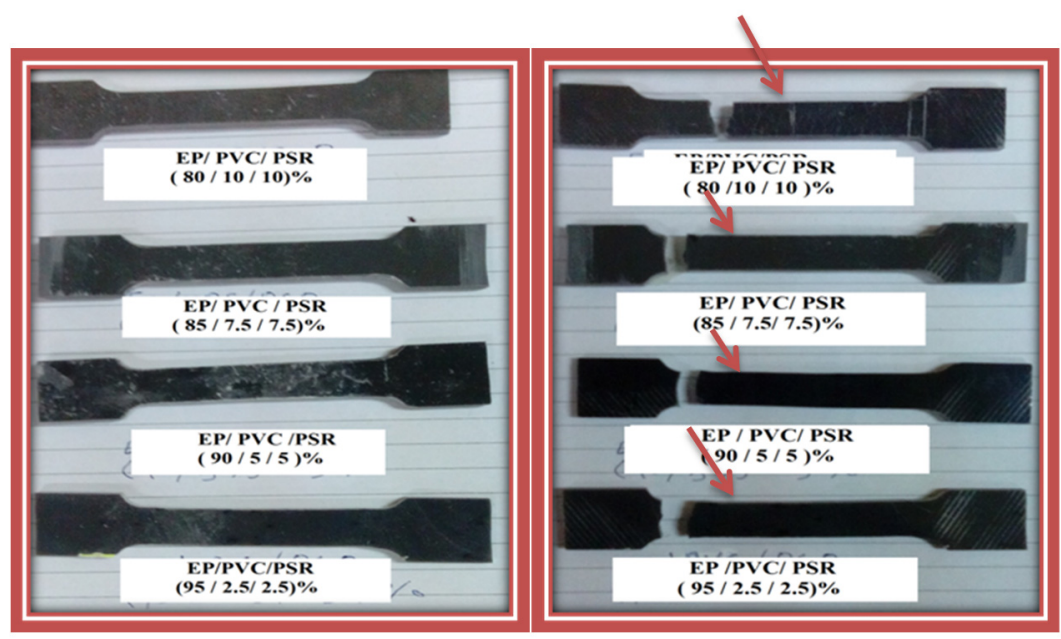

(a)

(b)

Figure 2. Photographic image of the tensile test samples (a) before the test, (b) after the test

\subsubsection{Impact Test}

Charpy impact test instrument, model IMI produced by AMITYVILLE/ New York, was used to determine the impact energy of the test samples after measuring their dimensions using the vernier. The instrument work is performed by lifting up the hammer to the highest point and fixing it, then the sample is put in its position after that all the potential energy will be change to the kinetic energy when the hummer freed and strike the sample. The gauge of instrument will read the energy value required to fracture the sample as shown in Figure 3. The samples subjected to this test are presented in Figure 4. The values of impact strength can be calculated by the equation (Meyers \& Chawal, 2009):

$$
\text { I.S }=\frac{U_{C}}{A}
$$

where $\left(U_{C}\right)$ is the fracture energy required to break the sample $(\mathrm{J}),(\mathrm{A})$ is the cross-sectional area of the sample $\left(\mathrm{mm}^{2}\right)$

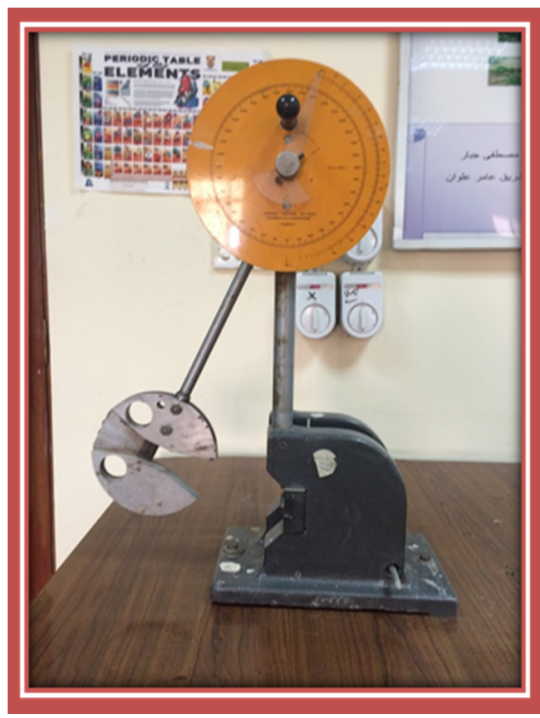

Figure 3. Charpy impact test 


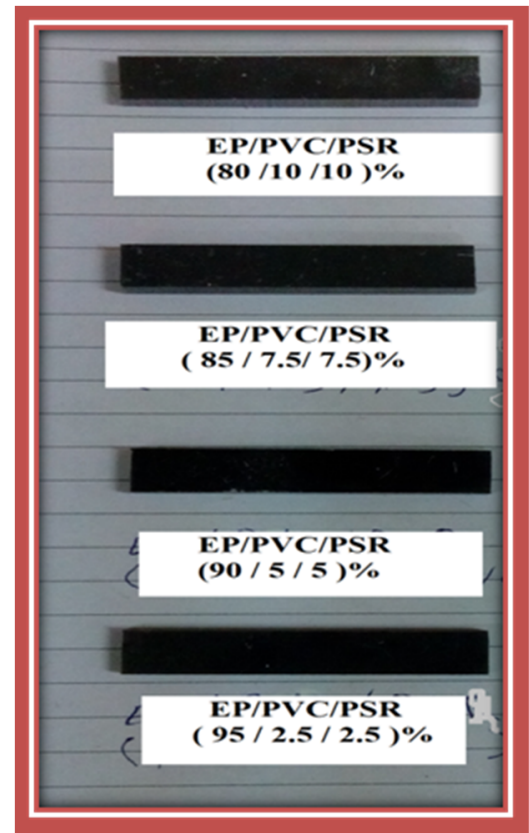

(a)

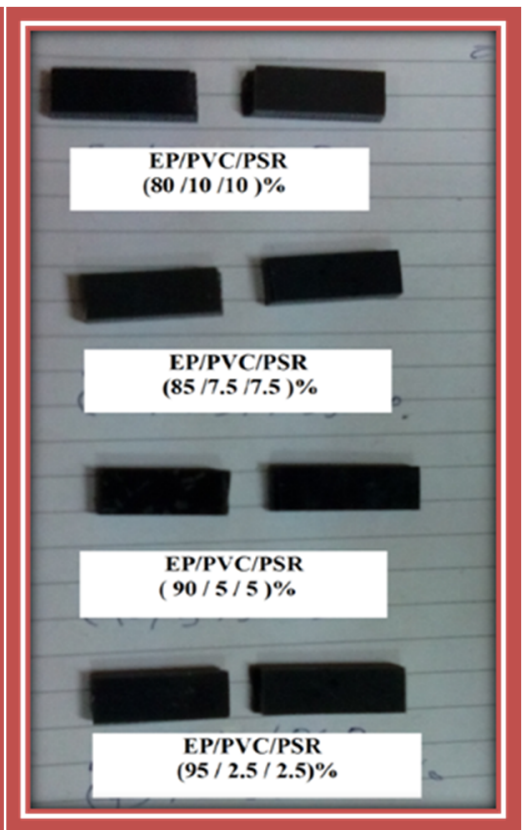

(b)

Figure 4. Photographic image of the impact test samples (a) before the test, (b) after the test.

\subsubsection{Flexural Test}

In this test, the sample was fixed on the two support points horizontally then the load was applied gradually on the sample to break. The same tensile device was used to perform this test by the computer screen connected with it. Figure 5 shows the sample subjected to the flexural test while Figure 6 illustrates photographic images of the prepared sample before and after the test.

Flexural strength (F.S) is calculated by the following equation (Crawford, 1998).

$$
\mathrm{F} . \mathrm{S}=\frac{3 P L}{2 b d^{2}}
$$

where (P) is the energy fracture and (L) is the sample length (b) is the sample width and (d) is the sample thickness

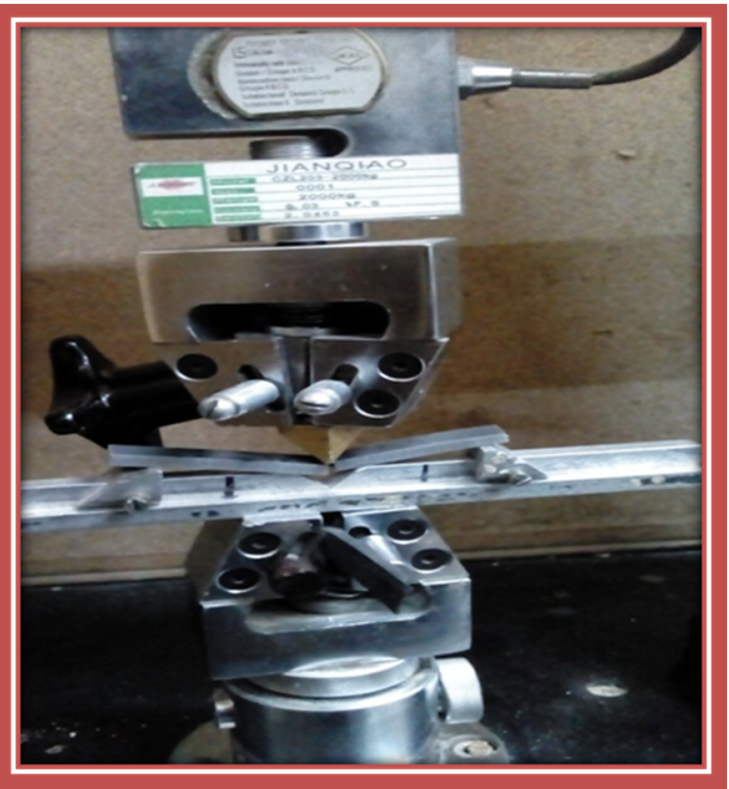

Figure 5. The sample under 3-point flexural test 


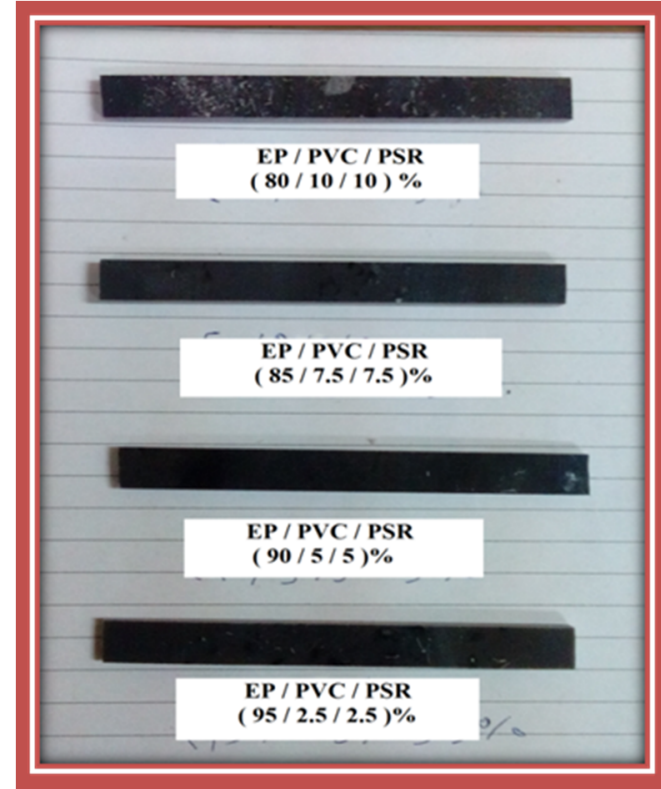

(a)

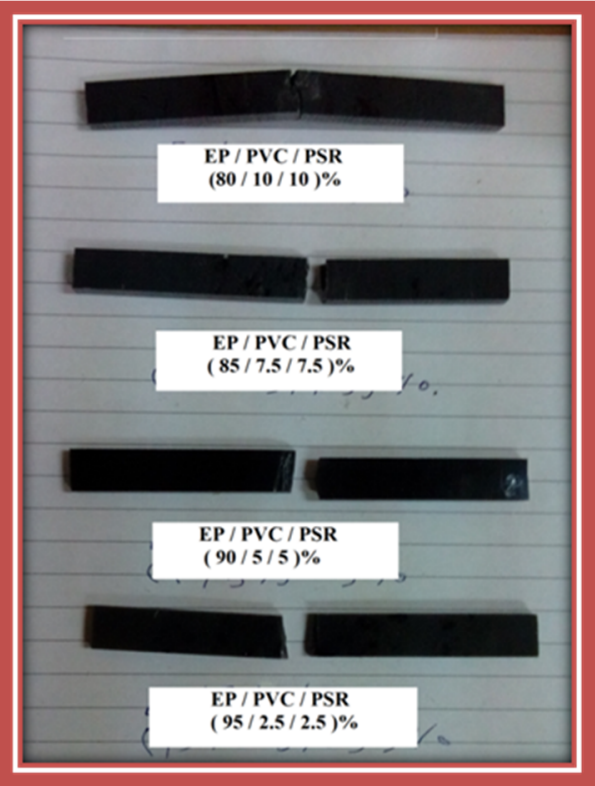

(b)

Figure 6. Photographic images of the flexural test samples (a) before the flexural test, b) after the flexural test.

\subsubsection{Compression Test}

The sample was put on the stand and by pressing on the piston continuously, the stand will rise with the sample and the sample will be exposed to pressure from two sides until it fails, the value of compressive strength can be determined by the following equation (Rajput, 2008):

$$
\text { C.S }=\frac{\sigma}{\varepsilon}
$$

Where $(\sigma)$ is the stress and $(\varepsilon)$ is the strain of sample.

Figure 7 shows the photographic image of the instrument and the prepared samples for the test.

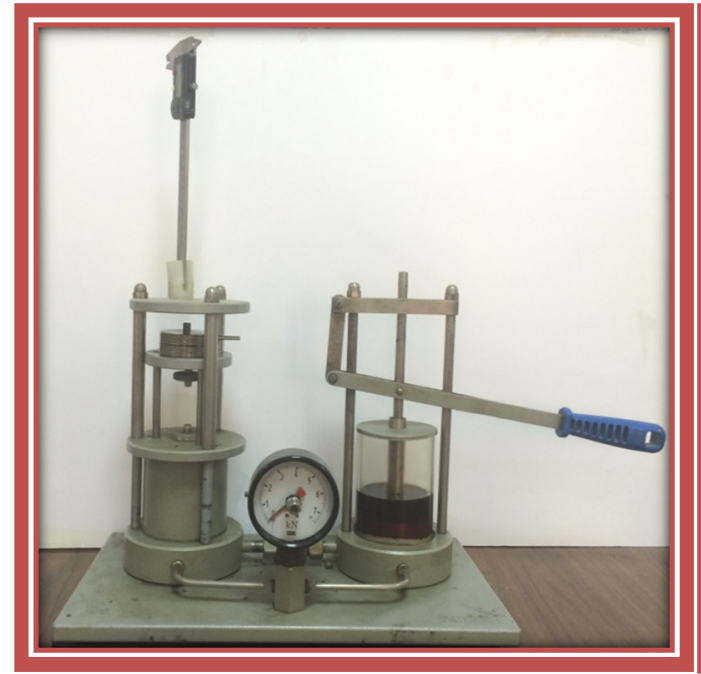

(a)

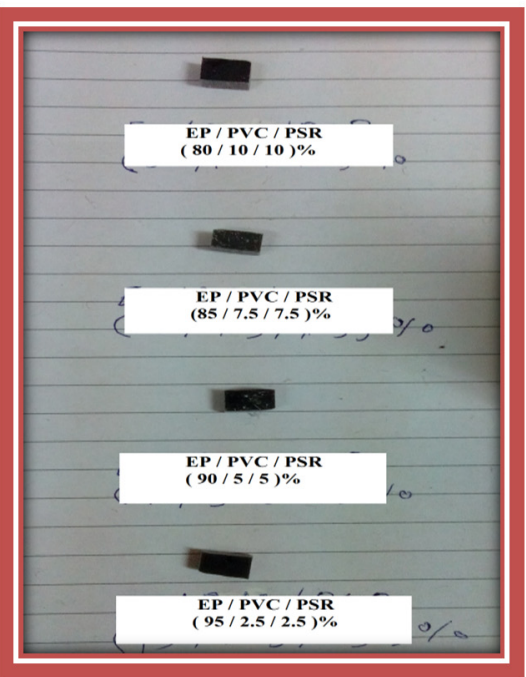

(b)

Figure 7. (a) Compression test instrument (b) test's samples 


\subsubsection{Hardness Test}

Shore D Hardness device was used to measure the depth of penetration of a specific indenter. The recorded reading of the hardness value is shown by Digital Screen connected with device. Figure 8 shows the instrument used for this test.

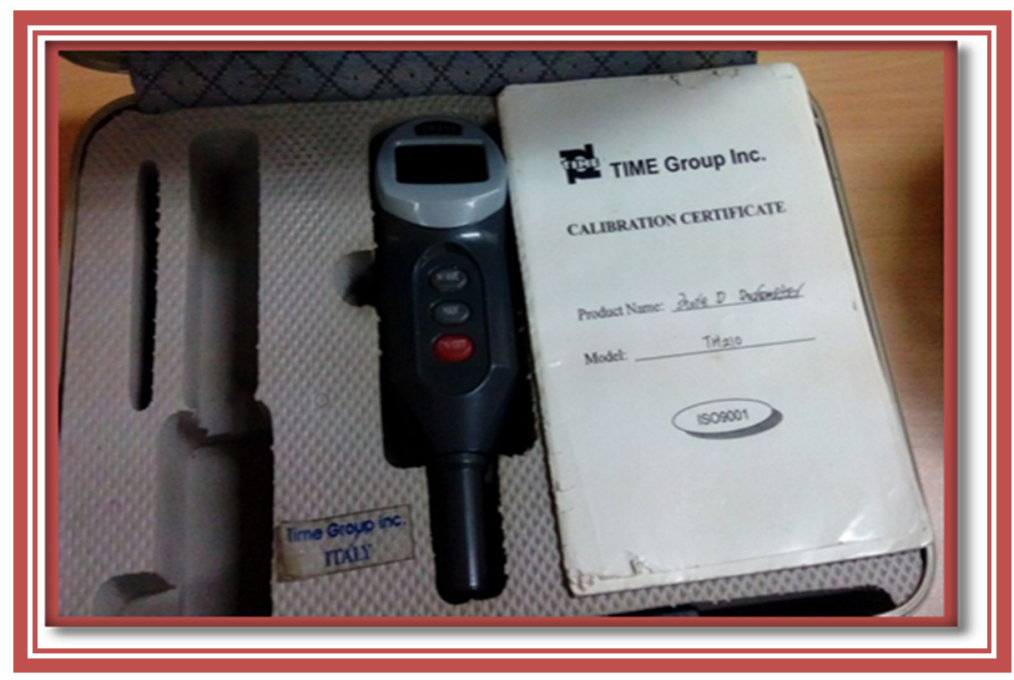

Figure 8. Shore D hardness test instrument

\section{Results and Discussion}

Figure 9 shows the relation between the tensile strength values with blending ratio for the two ternary blends under work, from this figure it can be noticed that tensile strength of epoxy resin decrease after blending it with (UP/PSR and PVC/ PSR). This behavior means that the presence the previews polymers within epoxy network structure leads to increase the ductility which causes in decreasing the ultimate tensile strength, it is also noticed that the blend (A) records the highest tensile strength values compared with the blend (B) at all blending ratios. The results of this this test agrees with that of the research (Awham \& Nada, 2014).

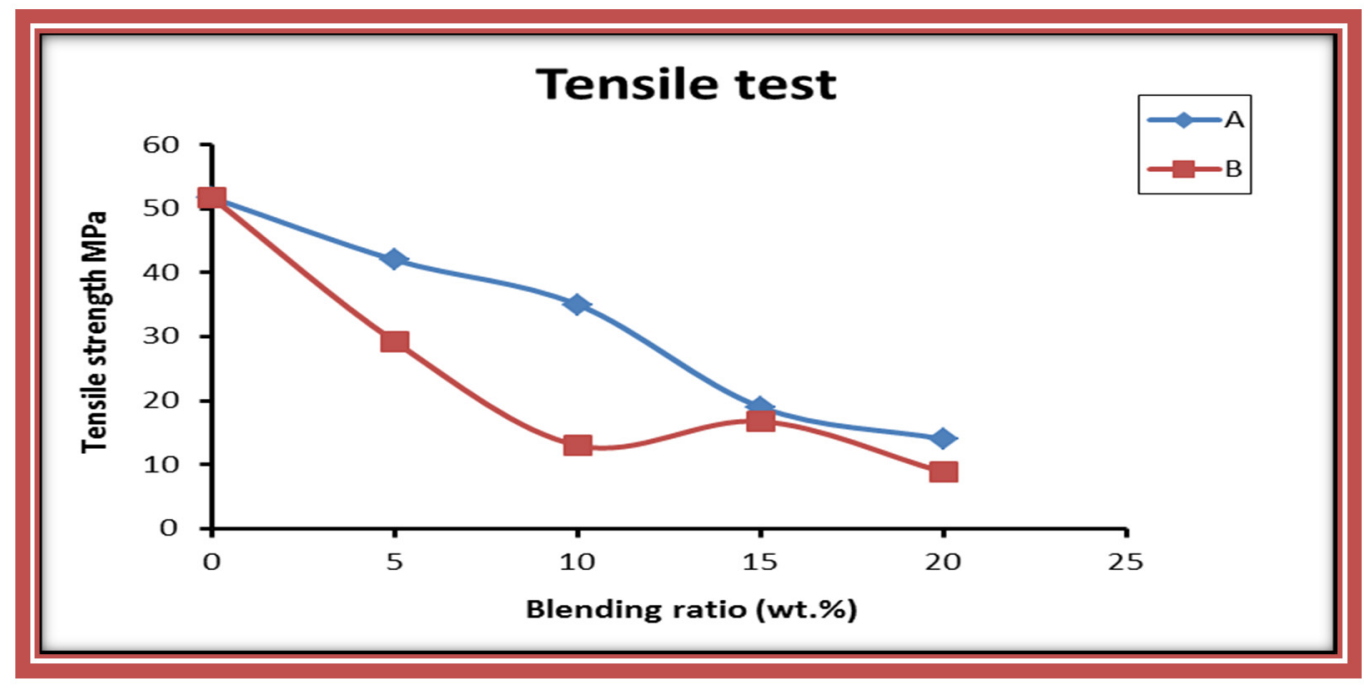

Figure 9. Tensile strength values as a function of blending ratio of ternary blends (A) and (B).

Figure 10 shows the relation between the impact strength values and the weight blending ratio of two ternary blends (A) and (B), from this figure it can be noted that the blend (A) records at ratio of (15 wt.\%) while the blend 
(B) gives the highest value at ratio of (20 wt.\%), this behavior may be related to the presence of (PVC) within the blend (B) which makes the blend behaves as ductile material, this result means that (PVC) leads to increasing the absorbed energy by the sample according to the eq.(2), the presence (UPE) in the ternary blend (A) causes increasing and decreasing of I.S frequently, this behavior depend on the penetrating nature between the three polymers for each mixing ratio. Other previous researches were obtained the same results of this test (Awham \& Entihaa, 2014; Awham \& Mays, 2016).

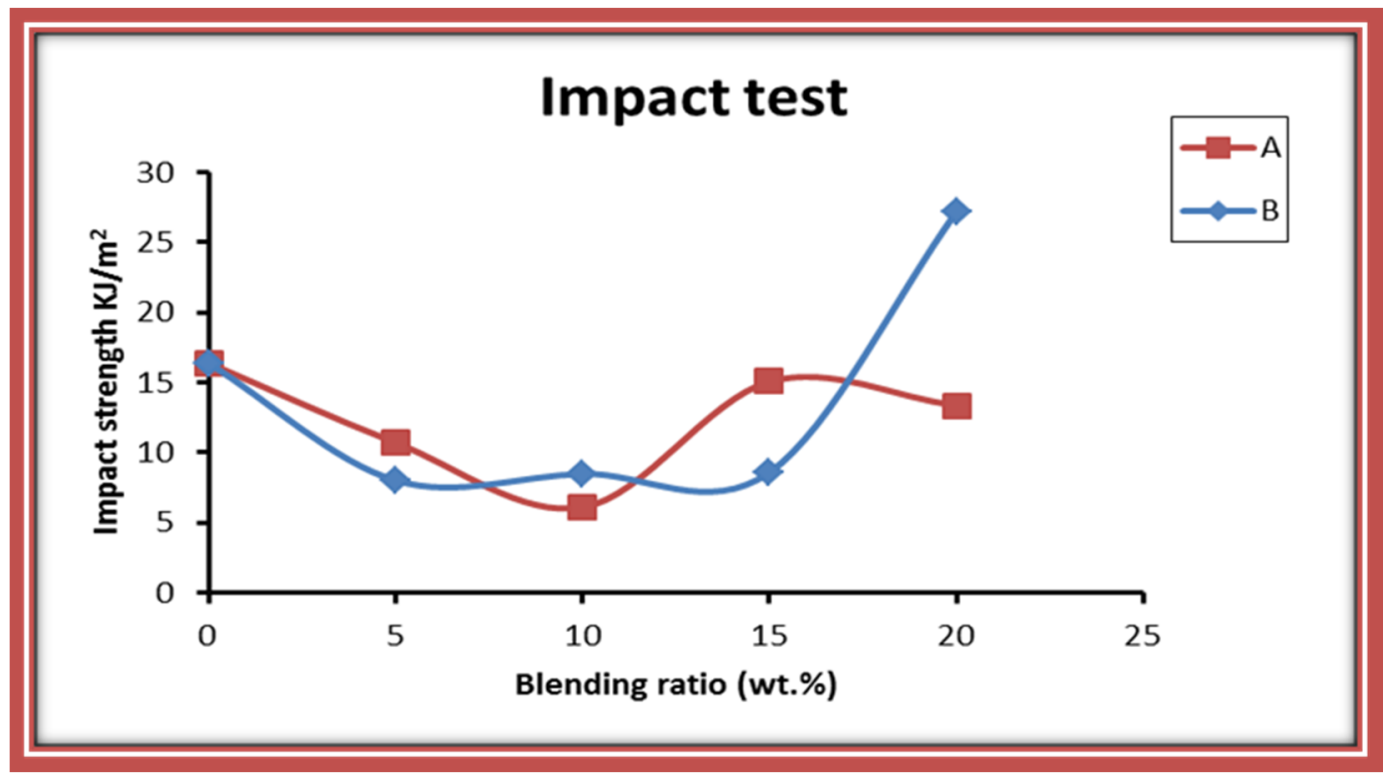

Figure 10. Impact strength values as a function of blending ratio of ternary blends (A) and (B)

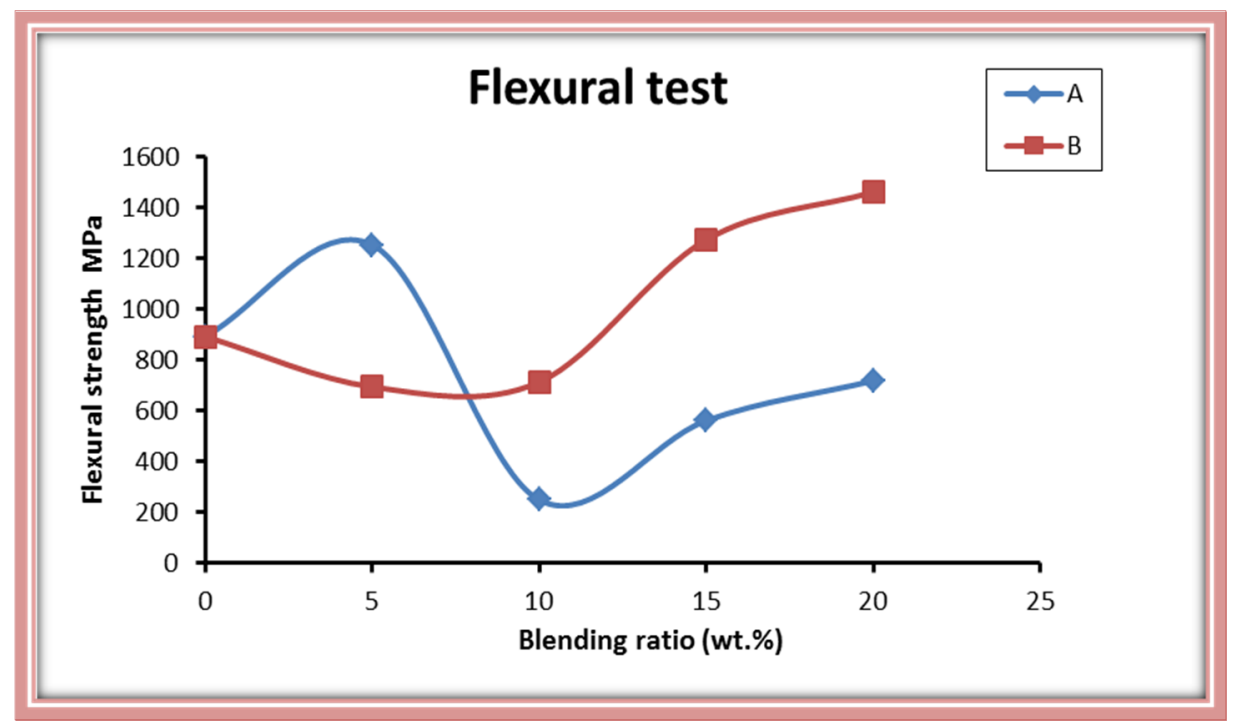

Figure 11. Flexural strength values as a function of blending ratios of ternary blends (A) and (B)

Figure 11 shows the relation between flexural strength values with blending ratio for the ternary blend under study, it can be concluded that the behavior of blend (A) different from that the behavior of blend (B). This difference depend on two factor, the first factor is the presence of polymer (UPE) in the blend (A) which consider brittle polymer which leading to increase the flexural strength value at the ratio $(5 \mathrm{wt} . \%)$ and then the flexural strength of blend (A) decreases with increasing of the blending ratio due to the occurring of the plasticization phenomenon (Liu, Zhong, \& Yu, 2010) especially at the ratio (10 wt.\%), the second factor return to presence the polymer (PVC) 
in the blend (B) which causes decreasing of flexural strength at the initial ratio of mixing but increasing at the higher ratios $(15,20 \mathrm{wt} . \%)$.

Figures 12 and 13 show the relation between stress and strain for the blend (A) and (B) at different blending ratio, it can be noticed that the values of strain for blend (B) is higher than that of blend (A), because of presence (PVC) within epoxy network structure which acts as plasticizing factor of it ratio (Biju, Radhakrishnan, Thomas, \& Gopinathan, 2007).

Figure 14 shows the relation between compressive strength value (C.S) with the blending ratio for the two ternary blends (A) and (B) under work, from this figure it can be noticed that the compression strength of epoxy resin decreases after blending it in blend (B) this behavior means that the presence (PVC) polymer within epoxy network structure leads to increase the ductility of this material (Barone \& Carciotto, 2006), but in the blend (A) it can be noticed that the presence of polymer (UPE) causes increasing and decreasing of (C.S) frequently.

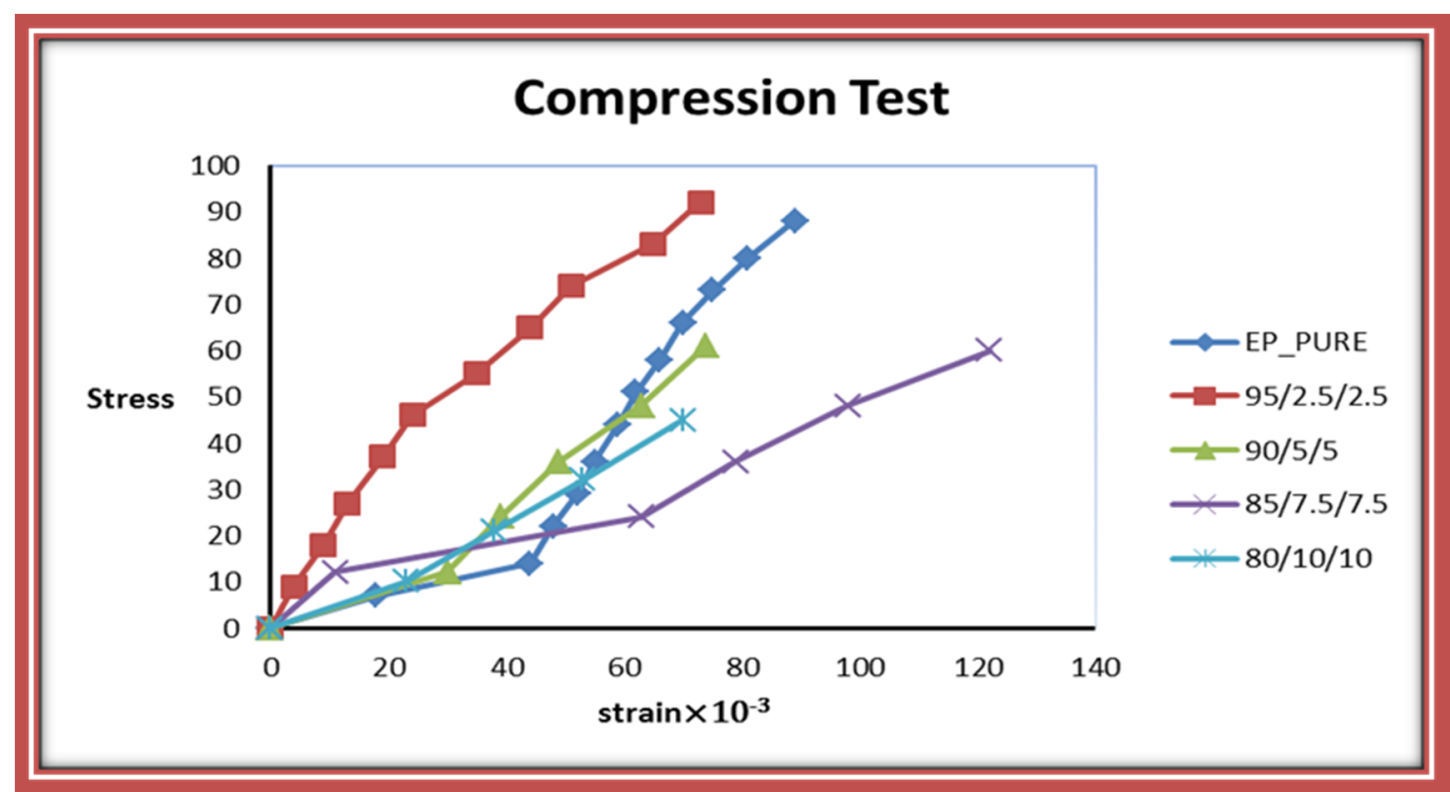

Figure 12. The relation between stress-strain of blending ratio of ternary blend (A)

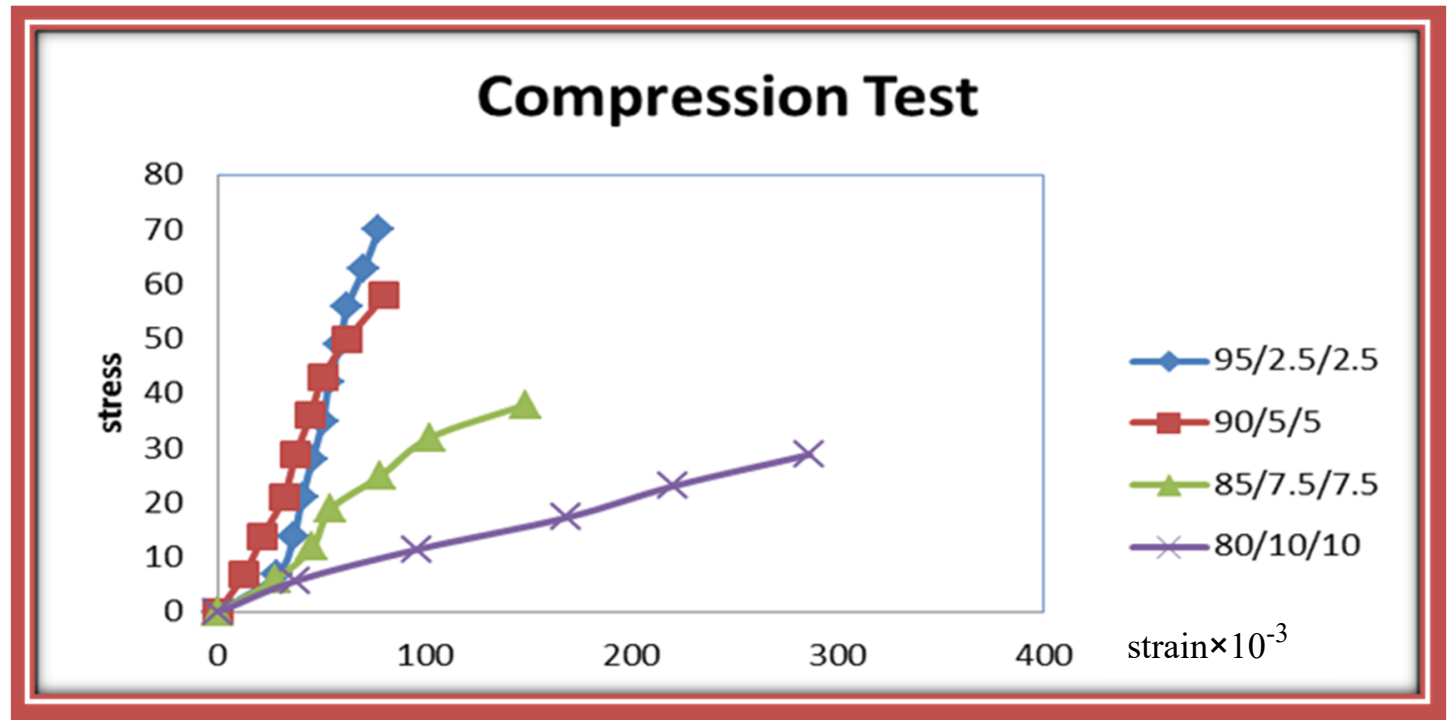

Figure 13. The relation between stress-strain of blending ratios of ternary blend (B) 


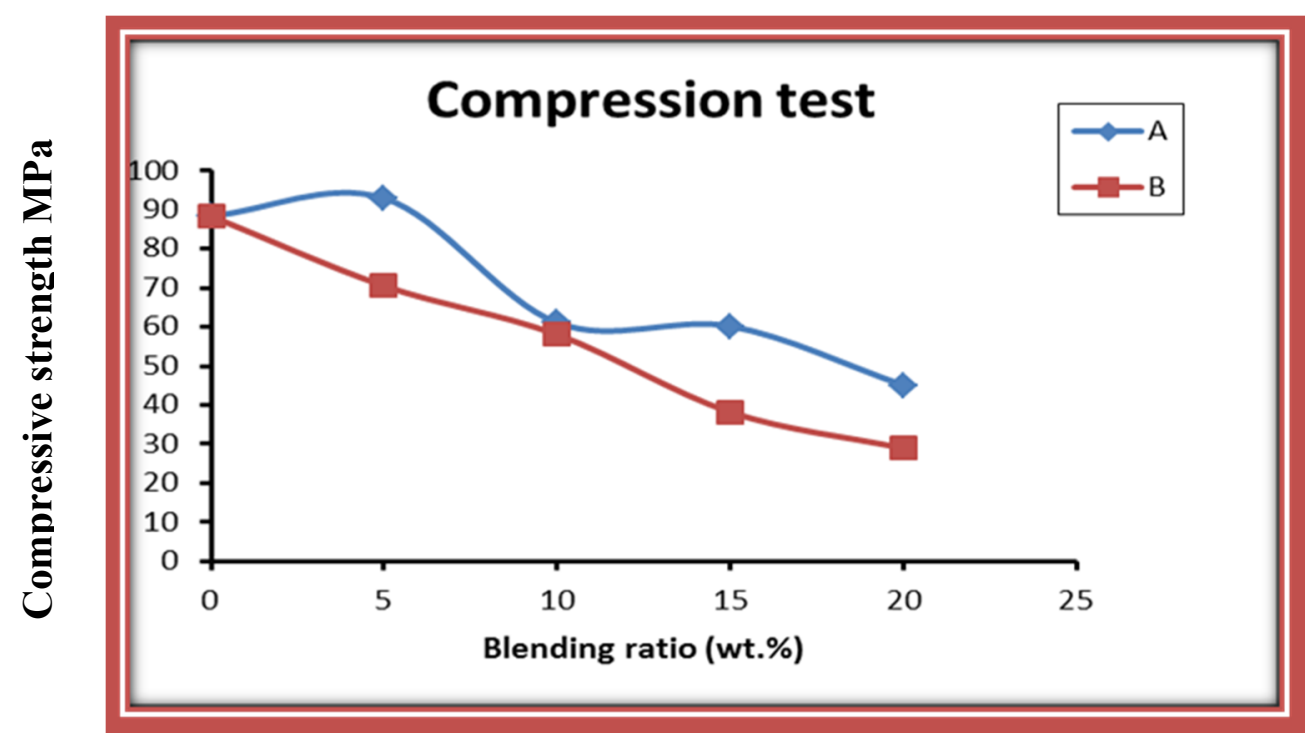

Figure 14. Compressive strength values as a function of blending ratios of ternary blends (A) and (B)

Figure 15 shows the relation between hardness number and blending ratio for the two ternary blend under work, from this figure it can be noticed that the hardness values are constant at the ratios ( 5 and $10 \mathrm{wt} . \%)$ but gradually decreases at the ratios (15 and 20 wt.\%). The reason behind this phenomenon is due to presence the added polymers (UPE and PVC) as well as the presence (SBR) for the blend (A) and (B) respectively which causes some decreasing in the hardness values because of these polymers drop the density of crosslinking of epoxy resin and then the values of hardness will be decreased (Bhuniya \& Adhikari, 2003).

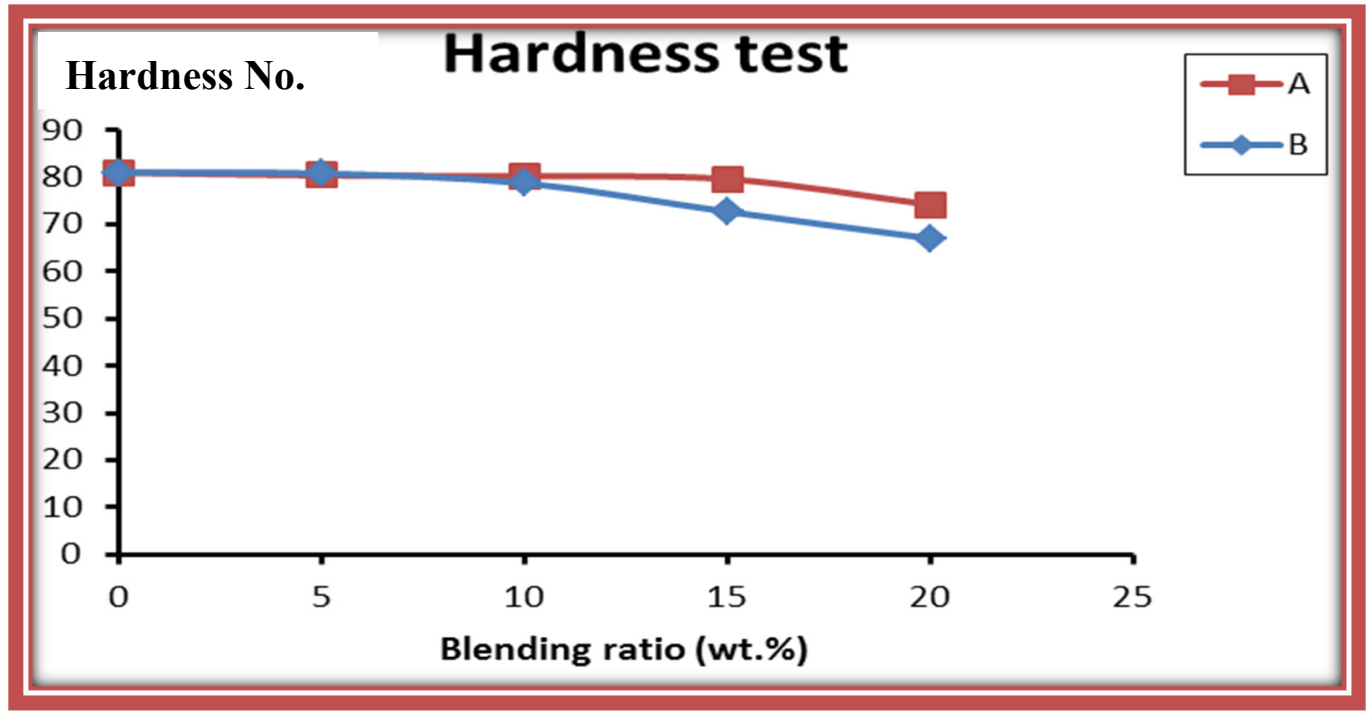

Figure 15. Hardness values as a function of blending ratios of ternary blends (A) and (B)

\section{Conclusions}

1) It can be concluded that the blend (EP/PVC/PSR) records the highest value of impact strength at (20wt. \%) of mixing ratio for added polymers but the lowest value of hardness at the same percent.

2) There is no phase separation phenomenon between the polymers after the blending.

3) It is clear that the color of each blend prepared changes depending on the blending ratio of added polymer. 


\section{References}

Arunhati, R. S., \& Arun, K. N. (2011). Mechanical, Thermal and Morphological Behavior of Thiol Terminated Liquid Polysulfide Modified- Epoxy Resin Blends. International J. of Plastic and Polym. Tech., 1(1), 1-15.

Awham, M. H., \& Entihaa, G. D. (2014). Mechanism of Hybrid Reinforcement and its Effect on some Properties of Binary Polymer Blend. Eng. \&Tech. J., 32(2), Part B, 287-301.

Awham, M. H., \& Mays, S. M. (2016). Preparation and Studying the Fracture Toughness of Laminate Composites. Eng. \&Tech. J., 34(4), Part B, 451-461.

Awham, M. H., \& Nada, R. K. (2014). Preparation \& Caracterization of Binary Polymer Blend Reinforced with Polypropylene, Carbon \& Hybrid Fibers. Jordan J. of Phy., 7(1), 13-22.

Ban, A. Y. (2010). Development and Characterization of Ternary Thermosetting Polymer Blends (Ph.D. Thesis, Department of Applied Sciences, University of Technology).

Barone, L., \& Carciotto, S. (2006). Cicala G. and Recca A.,"Thermomechanical Properties of Epoxy/Poly(E-caprolactone) blends. Polym. Eng. Sci., 46(11), 1576-1582. https://doi.org/10.1002/pen.20447

Bhuniya S., \& Adhikari B. (2003). Toughening of epoxy resins by hydroxy-terminated, siliconmodified polyurethane oligomers. Journal of Applied Polymer Science, 90(6), 1497-1506. https://doi.org/10.1002/ app. 12666

Biju P. K., Radhakrishnan M. N. , Thomas G. V., Gopinathan M. R. (2007). Plasticizing Effect of Epoxidized Natural Rubber on PVC/ELNR Blends Prepared by Solution Blending. Materials Science-Poland, 25(4), 919-932.

Crawford, R. J. (1998). Plastic Engineering (3rd ed.). Oxford: Elsevier Butterworth-Heinemann.

Kumar, K. D., \& Kothandaraman, B. (2008). Modification of (DGEBA) Epoxy Resin with Maleated Depolymerised Natural Rubber. Express Polym. Letters, 2(4), 302-311. https://doi.org/10.3144/ expresspolymlett.2008.36

Liu, Y., Zhong, X., \& Yu, Y. (2010). Gelation behavior of thermoplastic-modified epoxy systems during polymerization-induced phase separation. Colloid and Polymer Science, 288(16-17), 1561-1570. https://doi.org/10.1007/s00396-010-2288-5

Meyers, M. A., \& Chawal, K. K. (2009). Mechanical Behavior of Materials (2nd ed.). Cambridge University Press.

Rajput, R. K. (2008). Eng. Mat.. S. Chand, New Delhi.

Young, W. C., \& Budynas, R. G. (2002). Roark's Formulas for Stress and Strain (7th ed., p. 851). McGraw-Hill, Companies, Inc..

Zhu, G., Wang, F., Xu, K., Gao, Q., \& Lin, Y. (2013). Study on Properties of Poly (vinyl alcohol)/Polyacrylonitrile Blend Film. Polimeros, 23(20), 146-151. https://doi.org/10.4322/polimeros.2013.076

\section{Copyrights}

Copyright for this article is retained by the author(s), with first publication rights granted to the journal.

This is an open-access article distributed under the terms and conditions of the Creative Commons Attribution license (http://creativecommons.org/licenses/by/4.0/). 